\title{
POLÍTICAS PÚBLICAS DE RESSOCIALIZAÇÃO NA GESTÃO DO SISTEMA CARCERÁRIO DO RIO GRANDE DO SUL
}

\author{
PUBLIC RESOCIALIZATION POLICIES IN THE MANAGEMENT OF THE RIO \\ GRANDE DO SUL PRISON SYSTEM
POLÍTICAS DE RESOCIALIZACIÓN PÚBLICA EN LA GESTIÓN DEL SISTEMA PENITENCIARIO DE RIO GRANDE DO SUL

\author{
Cândida da Rosa Schepp ${ }^{1}$ \\ Dionatan dos Santos Duarte ${ }^{2}$ \\ Ricardo Bersch Borges ${ }^{3}$ \\ Rodrigo Rossi Martins ${ }^{4}$ \\ Adam Cristiano Acosta Pereira de Ávila ${ }^{5}$ \\ Leandro Carvalho da Silveira ${ }^{6}$
}

RESUMO: A principal intenção do sistema penitenciário é a organização das ocupações propostas na execução penal, tendo como objetivo a regeneração dos apenados, readaptando-os à vida social, com, por exemplo, o acesso à assistência educacional, trazendo um grande valor social, haja vista que a ressocialização de presos não escolhe etnia, classe social, idade, gênero, crença. O presente estudo busca analisar como perfectibilizar essa intenção. Como método de pesquisa, foi utilizada uma abordagem dedutiva, foram estudados os dados da ressocialização e o porquê da criação da lei de execução penal, onde está prevista, dentre outras, assistência educacional. Tem como objetivo estudar as políticas públicas de ressocialização previstas no âmbito nacional para a gestão do sistema penitenciário no estado do Rio Grande do Sul, e aborda conceitos e histórico sobre o sistema carcerário, leis e políticas públicas destinadas ao sistema carcerário brasileiro e os benefícios da educação carcerária.

Palavras-chave: Gestão Prisional. Políticas Públicas. Ressocialização.

\footnotetext{
I Graduada Bacharela em Direito pela Universidade Católica de Pelotas. Pós-graduada em Direito Penal e Processual Penal pelo Instituto Brasil de Ensino. Exerce cargo público de agente penitenciária. E-mail: candidaschepp@hotmail.com.

2 Graduado Bacharel em Direito pela Faculdade Anhanguera Educacional. Graduado Bacharel em Administração pela Universidade Norte do Paraná. Pós-graduado em Gestão Prisional pela Faculdade Venda Nova do Imigrante. Exerce cargo público de agente penitenciário. E-mail: dionatanduarte@gmail.com.

${ }^{3}$ Graduado em Licenciatura Plena em Educação Física pela Universidade Federal de Pelotas. Exerce cargo público de agente penitenciário. E-mail: ricardinhobersch@gmail.com

${ }^{4}$ Graduado em Licenciatura Plena em Matemática pela Universidade Católica de Pelotas. Exerce cargo público de agente penitenciário. E-mail: prof.rossi@hotmail.com.

${ }^{5}$ Graduado Bacharel em Direito pela Universidade Federal de Pelotas. Exerce cargo público de agente penitenciário. E-mail: adam_cristianor709@hotmail.com.

${ }^{6}$ Graduado Bacharel em Fisioterapia pela Faculdade Anhanguera do Rio Grande. Exerce cargo público de agente penitenciário. E-mail: leandrofisiocarvalho@gmail.com
} 
ABSTRACT: The main intention of the penitentiary system is the organization of the occupations proposed in the penal execution, aiming at the regeneration of the inmates, readapting them to social life, with, for example, access to educational assistance, bringing a great social value, given that that the rehabilitation of prisoners does not choose ethnicity, social class, age, gender, belief. The present study seeks to analyze how to perfect this intention. As a research method, a deductive approach was used, the data of resocialization and the reason for the creation of the law of penal execution were studied, which provides, among others, educational assistance. It aims to study the public policies of resocialization planned at the national level for the management of the penitentiary system in the state of Rio Grande do Sul, and addresses concepts and history about the prison system, laws and public policies aimed at the Brazilian prison system and the benefits of prison education.

Keywords: Prison Management. Public policy. Resocialization.

REANUDAR: La intención principal del sistema penitenciario es la organización de las ocupaciones propuestas en la ejecución penal, visando la regeneración de los internos, readaptándolos a la vida social, con, por ejemplo, acceso a asistencia educativa, trayendo un gran valor social, dado que la rehabilitación de los presos no elige etnia, clase social, edad, género, creencia. El presente estudio busca analizar cómo perfeccionar esta intención. Como método de investigación se utilizó un enfoque deductivo, se estudiaron los datos de la resocialización y el porqué de la creación de la ley de ejecución penal que brinda, entre otros, asistencia educativa. Tiene como objetivo estudiar las políticas públicas de resocialización planificadas a nivel nacional para la gestión del sistema penitenciario en el estado de Rio Grande do Sul, y aborda conceptos e historia sobre el sistema penitenciario, leyes y políticas públicas dirigidas al sistema penitenciario brasileño. y los beneficios de la educación en prisión.

Palabras clave: Gestión Penitenciaria. Políticas públicas. Resocialización.

\section{INTRODUÇÃO}

O Direito Penal até o século XVIII, segundo Carvalho Filho (2002), era marcado por penas cruéis e desumanas, não havendo à época privação de liberdade como forma de pena, apenas como custódia, com o fim de garantir que o acusado não fugiria e também para a produção de provas por meio da tortura - forma de obtenção de provas legítima na época - o acusado, então, aguardava o julgamento e a pena. O encarceramento era um meio e não o fim para a punição.

Conforme Souza (2015), o primeiro estabelecimento penal brasileiro surgiu no ano de 1769, denominado Casa de Correção do Rio de Janeiro. Na época, não existia uma Constituição brasileira, já que o Brasil ainda era uma colônia portuguesa, e a construção da 
prisão foi determinada pela Carta Régia, um documento do Rei de Portugal que regia aquilo que deveria ser feito na colônia. Após a independência do Brasil, surgiu a primeira Constituição brasileira, que determinou a separação de presos por tipo de crimes e penas aplicadas e também a adaptação das cadeias.

O presente estudo possui relevância social, a escolha do tema é de interesse jurídico, público e psicológico, haja vista que a ressocialização de presos não escolhe etnia, classe social, idade, gênero, crença. O tema ressocialização deveria ser tratado com mais seriedade pela sociedade, um tratamento com a devida seriedade impõe a execução de políticas públicas para diminuir retorno aos cárceres brasileiros.

O presente trabalho tem, como método de pesquisa, uma abordagem dedutiva, tendo em vista que primeiramente é feita uma análise dos dados da ressocialização dos apenados no estado do Rio Grande do Sul. Ressalta-se que esse método é de suma importância, pois possibilita que seja estudado os dados da ressocialização e o porquê da criação da lei de execução penal, onde está previsto, dentre outras, assistência educacional.

Já os métodos de procedimentos são na forma de dados estatísticos e contexto histórico. Com esses procedimentos é possível fazer um contexto histórico e estatístico de como são os casos de ressocialização carcerária no estado Rio Grande do Sul.

As técnicas de pesquisa são da forma indireta, com pesquisa bibliográfica e documentais, tais como, pesquisas documentais, dados estatísticos e leis, pois essas técnicas possibilitam que a pesquisa aborde o assunto com mais propriedade.

O trabalho a seguir tem o objetivo de estudar as políticas públicas de ressocialização previstas no âmbito nacional para a gestão do sistema penitenciário, focando no estado do Rio Grande do Sul. Está dividido em três seções e aborda conceitos e histórico sobre o sistema carcerário brasileiro, também fala das leis e políticas públicas destinadas ao sistema carcerário brasileiro e dos benefícios da educação carcerária.

\section{EVOLUÇÃO HISTÓRICA DO SISTEMA CARCERÁRIO NACIONAL}

O Brasil era uma colônia portuguesa até ı8zo e não tinha um Código Penal próprio. Conforme Souza (2015), o Brasil se submetia, assim, às Ordenações Filipinas, as quais, em seu livro V, traziam, em seu rol, os crimes e as penas, entre elas as penas de morte, penas corporais - açoite, mutilação, queimaduras-, confisco de bens, multa e penas como 
humilhação pública do réu, não existindo a previsão da privação de liberdade. As ordenações são do século XVII e os movimentos reformistas penitenciários começam a tomar forma somente no final do século seguinte.

Mesmo naquela época, não demorou muito para que o problema de superlotação prisional acontecesse, pois o número de condenados era muito maior de que o número de vagas nos presídios existentes no momento, afinal, as casas prisionais seguiam o entendimento antigo, de que a prisão era um meio para evitar fuga para o fim pena. Segundo Souza (2015), com o fito de tornar mínimo o problema da superlotação prisional, que se agravava cada dia, por volta de I890, o código penal já antecipava a transferência de presos com bom comportamento que haviam cumprido parte da pena para casas prisionais agrícolas.

O Código Penitenciário da República, em 1935, trouxe que o sistema penitenciário precisaria não apenas castigar e punir, mas principalmente buscar a regeneração dos detentos. Trazendo, assim, uma sugestão para que os apenados pudessem sair do cárcere recuperados e em condições de conviver com a sociedade como uma pessoa qualquer.

Foi desde então que as prisões e os sistemas de punições se transformaram, por meio de um movimento que requereu as mais expressivas mudanças na compreensão das penas privativas de liberdade, trazendo a criação e a construção de prisões organizadas para a correção dos apenados até os dias de hoje.

A partir desse entendimento, a punição passou a estabelecer um novo método de disciplina, eliminando da prisão o seu caráter de rebaixamento moral e físico. A lei penal passou a ser uma função de prevenção do delito e readaptação do apenado.

Para Foucault (1987) a intenção da prisão deixou de causar dor física e o objeto da punição deixou de ser o corpo para atingir a moral do infrator. A prisão surge como pena privativa de liberdade e traz uma nova estratégia para o fazer sofrer. Assim, o autor (1987, p. 196) diz que "retirando tempo do condenado, a prisão parece traduzir concretamente a ideia de que a infração lesou, mais além da vítima a sociedade inteira”.

Foucault (1987), ainda, traz em seus estudos que as prisões observadas sobre o olhar do Estado torna-se mais adequado vigiar do que punir, pois, vigiar as pessoas e conservar esse processo é um modo para que elas não infrinjam a ordem, as leis e nem ameacem o sistema. 
A prisão passa a se basear teoricamente no que é hoje, privando o indivíduo de liberdade para que ele possa aprender através do isolamento, retirando-o da família e de outras relações sociais, levando o mesmo a refletir sobre seu ato criminoso, tornando, então, a representação mais direta de sua punição.

Segundo dados do Departamento Penitenciário - DEPEN - (2016), no período entre I990 e 2015, a população carcerária brasileira passou de 90 mil para mais de 600 mil, um crescimento de quase $600 \%$. Além desses presos, que se encontram nas 1478 casas penais públicos espalhados pelo território brasileiro, ainda existem mais de roo mil que cumprem pena em prisão domiciliar.

\section{LEIS E POLÍTICAS PÚBLICAS DESTINADAS AO SISTEMA CARCERÁRIO}

A atual Constituição Federal, criada em um estado Democrático de Direito, nos traz, ao longo de seu texto uma série de direitos e garantias fundamentais do indivíduo, sobretudo no rol do caput de seu artigo $5^{\circ}$, buscando alçar a dignidade humana como bem maior a ser protegido pelo Estado.

Ela também proíbe expressamente a prática de tortura, tratamentos desumanos e punições cruéis ao indivíduo encarcerado, elenca diversos direitos que devem ser garantidos também ao violador da lei penal, os quais estão dispostos de forma mais detalhada no artigo 4I da Lei de Execução Penal (LEP - Lei 7.210/1984):

\footnotetext{
Art. 4I - Constituem direitos do preso:

I - alimentação suficiente e vestuário;

II - atribuição de trabalho e sua remuneração;

III - Previdência Social;

IV - constituição de pecúlio;

$\mathrm{V}$ - proporcionalidade na distribuição do tempo para o trabalho, o descanso e a recreação;

VI - exercício das atividades profissionais, intelectuais, artísticas e desportivas anteriores, desde que compatíveis com a execução da pena;

VII - assistência material, à saúde, jurídica, educacional, social e religiosa; [...]
}

A edição da Lei 7.210/84 - Lei de Execução Penal - permitiu a entrada no ordenamento jurídico de diversos dispositivos com caráter de humanidade das sanções, sempre no sentido de desenvolver de forma mais efetiva os Direitos Humanos. Por isso, a 
Lei de Execução Penal, manifesta a necessidade de diminuir as violações que ocorrem no cárcere e, ainda, a importância de se preservar os direitos do preso, tal como, a educação.

A Constituição Federal de 1988, nos traz no artigo 205 que:

A educação, direito de todos e dever do Estado e da família, será promovida e incentivada com a colaboração da sociedade, visando ao pleno desenvolvimento da pessoa, seu preparo para o exercício da cidadania e a sua qualificação para o trabalho.

A Constituição Federal colocou no artigo 208, Inciso I, a garantia da "educação básica obrigatória e gratuita dos 4 aos 17 anos de idade, assegurada inclusive sua oferta gratuita para todos os que a ela não tiveram acesso na idade própria”. Com base nisso, a educação precisa conduzir definições presentes na vida concreta de quem se pretendem educar ou reeducar; de modo diferente, não produz resultado, que é a aprendizagem.

Com isso, a Lei de Execuções Penais (LEP - Lei 7.210/1984) traz:

Art. 17. A assistência educacional compreenderá a instrução escolar e a formação profissional do preso e do internado.

Art. I8. O ensino de Io grau será obrigatório, integrando-se no sistema escolar da Unidade Federativa.

Art. I8-A. O ensino médio, regular ou supletivo, com formação geral ou educação profissional de nível médio, será implantado nos presídios, em obediência ao preceito constitucional de sua universalização. (Incluído pela Lei no 13.163, de 2015)

§ 1o $\mathrm{O}$ ensino ministrado aos presos e presas integrar-se-á ao sistema estadual e municipal de ensino e será mantido, administrativa e financeiramente, com o apoio da União, não só com os recursos destinados à educação, mas pelo sistema estadual de justiça ou administração penitenciária. (Incluído pela Lei no 13.163, de 2015)

§ 20 Os sistemas de ensino oferecerão aos presos e às presas cursos supletivos de educação de jovens e adultos. (Incluído pela Lei nº 13.163, de 2015)

§ 30 A União, os Estados, os Municípios e o Distrito Federal incluirão em seus programas de educação à distância e de utilização de novas tecnologias de ensino, o atendimento aos presos e às presas. (Incluído pela Lei no 13.163 , de 2015)

Art. I9. O ensino profissional será ministrado em nível de iniciação ou de aperfeiçoamento técnico.

Parágrafo único. A mulher condenada terá ensino profissional adequado à sua condição.

Segundo o Departamento Penitenciário Nacional (DEPEN, 2019), o Programa de Capacitação Profissional e Implantação de Oficinas Permanentes (PROCAP) é o principal programa implantado e incentivado pelo governo. O programa foi iniciado em 2012, e seu objetivo foi de implantar oficinas permanentes no maior número possível de estabelecimentos penais em todo o país, disponibilizando às pessoas privadas de liberdade 
o acesso à capacitação profissional. O PROCAP propende a implantação de oficinas nas áreas da construção civil, padaria e panificação, corte e costura industrial, marcenaria e informática.

Deve ser tratado o problema de baixo grau de instrução da população carcerária. Segundo o Conselho Nacional de Justiça (CNJ) e o InfoPen do Ministério da Justiça (2019), na população carcerária brasileira, $86 \%$ dos presos não concluíram a educação básica, 71\% não chegaram sequer a concluir o ensino fundamental e 6,1\% são totalmente analfabetos.

\section{EDUCAÇÃO CARCERÁRIA}

O Departamento Penitenciário Nacional, através da Coordenação de Educação, Esporte e Cultura da Coordenação-Geral de Promoção da Cidadania, é responsável pelo desenvolvimento das Políticas de Promoção e Acesso à educação no âmbito do Sistema Prisional. Segundo o DEPEN (2019) as ações educacionais são executadas diametralmente pelos Estados e pelo Distrito Federal, com apoio do Ministério da Justiça e Segurança Pública e do Ministério da Educação. Assim, considerando que a educação é um direito de todos e tem um papel transformador na sociedade, o DEPEN (2019) foca no papel da escola pública e dos espaços educativos como tática essencial de combate à desigualdade no sistema prisional brasileiro. É importante ressaltar que as pessoas privadas de liberdade perdem a liberdade de ir e vir, todavia, mantêm a titularidade de seus direitos fundamentais, dentre eles à educação, e todas devem ser alcançadas pelas políticas públicas idealizadas e implementadas pelos governos.

A primeira unidade prisional gaúcha baseada em um método que prevê a ressocialização humanizada dos apenados foi inaugurada no ano de 2018, conforme informação da Secretaria de Segurança Pública do Rio Grande do Sul. Essa nova unidade prisional foi produto de uma parceria entre o governo do Estado, o Ministério Público do Rio Grande do Sul (MPRS), o Poder Judiciário e a Associação de Proteção e Assistência aos Condenados (APAC) - Partenon. A estrutura fica localizada na Zona Leste de Porto Alegre, no espaço onde antes existia o Instituto Penal Pio Buck. Trata-se do rebatizado Centro de Reintegração Social Pio Buck. 
Essas unidades prisionais vêm para gerar a humanização das prisões, sem deixar de lado a finalidade punitiva da pena. $O$ modelo se destina aos apenados que estejam cumprindo pena privativa de liberdade em regime fechado, semiaberto ou aberto.

Durante o período de reclusão, o apenado deve participar das atividades propostas, de acordo com o seu regime prisional. Além do estudo, estão disponíveis oficinas, que visam ao aprendizado de um novo ofício, com o intuito de promover a reinserção no mercado de trabalho.

Segundo a Secretaria de Segurança Pública do Rio Grande do Sul (2018), a unidade deu início a um processo que visa a colocar em prática, em todo o RS, uma metodologia considerada eficaz contra a reincidência criminal. No modelo prisional tradicional, os indicadores chegam a 75\%. No novo modelo, o índice fica abaixo de $10 \%$.

Segundo a SUSEPE (2020), no mês de maio de 2020, as penitenciaras gaúchas contabilizam um total de 35.632 apenados do sexo masculino e r.766 de apenadas do sexo feminino. Os dados estatísticos sobre o grau de instrução da população carcerária no Rio Grande do Sul nos traz um total de $60,87 \%$ da população carcerária masculina com o ensino fundamental incompleto, já com o ensino fundamental completo está $13,37 \%$ da população carcerária, logo com 12,33\% está a população carcerária com o ensino médio incompleto e $6,47 \%$ com o ensino médio completo, já os outros $6,96 \%$ está entre a população carcerária que são analfabetos, ensino superior completo e incompleto. Já os dados com a população carcerária feminina trazem um pouco de diferença nos graus de instruções, mostrando que a população carcerária feminina que tem o ensino fundamental incompleto é de 23,91\%, menos da metade se comparar com o sexo masculina. Também traz 2I,09 que tem o ensino fundamental completo, já com ensino médio incompleto é de 23,91\% e 19,91 com o ensino médio completo, os outros $11,18 \%$ são de analfabetas e ensino superior completo e incompleto.

Desde 2013, o sistema prisional inseriu ações do Programa Nacional de Acesso ao Ensino Técnico e Emprego (PRONATEC), onde foi firmada a oferta de 90 mil vagas às pessoas privadas de liberdade, aos egressos e cumpridores de alternativas penais, iniciando as capacitações e qualificações profissionais. 


\section{CONSIDERAÇÕES FINAIS}

A educação é importante na ressocialização, pois, conforme dados trazidos neste trabalho, a maioria dos apenados tem baixos índices de escolaridade. Assim, um número significativo não domina níveis básicos de leitura e escrita, e esse baixo nível de escolaridade pode afetar suas vidas, por isso os programas e projetos de educação nas casas prisionais são importantes para desenvolvimento dos apenados no seu senso de autovalorização.

A educação é um direito de todos e as políticas e ações que estão nos dispositivos das leis precisam realmente fazerem parte da rotina das casas prisionais, não somente como algo independente e preciso, mas como uma política universal de Estado.

A educação é estimada como um processo promissor para a reintegração social do apenado. Além disso, é um direito que deve ser assegurado a todas as pessoas, independentemente de sua situação. É um direito que potencializa o exercício de outros direitos como o trabalho, a saúde e a participação cidadã.

O estado do Rio Grande do Sul começa a mostrar experimentos prósperos de ressocialização de presos através de parcerias com organizações não-governamentais, igrejas e familiares dos presos.

Portanto, não restam dúvidas de que o papel da educação no sistema prisional deve ser de reeducar e auxiliar os apenados a terem uma visão mais aberta de mundo, para a inserção novamente na sociedade, pois os apenados que têm acesso à escola estão mais qualificados para o mercado de trabalho. É através do ensino e da educação que os apenados têm a oportunidade de se humanizar e de se transformar. A educação é transformadora quando se quer transformar.

\section{REFERÊNCIAS}

CARVAlHO FILHO, Luiz Francisco. A prisão. São Paulo: Publifolha, 2002. p. 2I. FOUCAULT, Michel. Vigiar e punir: nascimento da prisão. $5^{-\mathrm{a}}$ ed. Petrópolis: Vozes, 1987. SOUZA, Fátima. A história do sistema prisional no Brasil. Disponível em: 〈http://pessoas.hsw.uol.com.br/prisoes2.htm〉 Acesso em: 20 fev. 2022. 
BRASIL. Constituição Federal de 1988. Disponível em: 〈http:// www.planalto.gov.br /Constituicao/ConstituicaoCompilado.htm>. Acesso em: 20 fev. 2022.

BRASIL. Lei n.o 7.210, de II de julho de 1984. Disponível em: 〈http://www.planalto.gov.br/ccivil_03/LEIS/L7210.htm.> Acesso em: 20 fev. 2022.

PENITENCIÁRIOS, Superintendência dos Serviços - SUSEPE. Disponível em: 〈http://www.susepe.rs.gov.br/conteudo.php?cod_menu=34〉 Acesso em: 20 fev. 2022.

PÚBLICA, Secretaria de Segurança.Disponível em: <https://estado.rs.gov.br/inauguradoo-primeiro-presidio-com-ressocializacao-humanizada-do-rs $>$ Acesso em: 20 fev. 2022.

NACIONAL, Departamento Penitenciário. Disponível em: <http://depen.gov.br /acessoa-informacao/acoes-e-programas> Acesso em: 20 fev. 2022.

NACIONAL, DepartamentPenitenciário. Disponível em: 〈http://depen.gov.br/DEPEN〉 Acesso em: 20 fev. 2022. 